Wilfrid Laurier University

Scholars Commons @ Laurier

Geography and Environmental Studies Faculty

Publications

Geography and Environmental Studies

$10-3-2012$

\title{
The Housing Preferences and Location Choices of Second Generation South Asians Living in Ethnic Enclaves
}

Virpal Kataure

Wilfrid Laurier University

Margaret Walton-Roberts

Wilfrid Laurier University, mwaltonroberts@wlu.ca

Follow this and additional works at: https://scholars.wlu.ca/geog_faculty

Part of the Geography Commons

\section{Recommended Citation}

Kataure, V. and M. Walton-Roberts (2012). The Housing Preferences and Location Choices of Second Generation South Asians Living in Ethnic Enclaves. South Asian Diaspora 5(1):57-76. DOI: 10.1080/ 19438192.2013.722385.

This Article is brought to you for free and open access by the Geography and Environmental Studies at Scholars Commons @ Laurier. It has been accepted for inclusion in Geography and Environmental Studies Faculty Publications by an authorized administrator of Scholars Commons @ Laurier. For more information, please contact scholarscommons@wlu.ca. 


\section{The Housing Preferences and Location Choices of Second Generation South Asians Living in Ethnic Enclaves}

\section{Introduction}

Immigrants have had an immense impact on the Canadian landscape by shaping physical and social environments through the development of culturally distinct ethnic enclaves. As these ethnic enclaves continue to grow (Qadeer \& Agrawal, 2010), the settlement choices of their offspring, known as the second generation, have become of great interest (Alba, Logan, Stults, Marzan, \& Zhang, 1999; Mendez, 2009; Reitz J. , 2002)..$^{1}$ It is important to understand the future housing and residential location choices of immigrant offspring to determine if they will reproduce the residential settlement patterns of their parents. In 2006, second generation Canadians comprised about 15\% of the total population in Canada (Picot \& Hou, 2011) and this population will continue to grow with the high levels of immigration. With extensive research conducted on immigrant ethnic clusters and segregation in Canada's major metropolitan centres (Agrawal S. K., 2006; Driedger, 2003; Fong, 1996; Haan, 2007; Myles \& Hou, 2003; Ray, 1999; Walks \& Bourne, 2006), implications of specific second generation visible minority residential patterns outside of urban centres have yet to be fully explored in the Canadian context. This paper takes an initial step toward that goal.

This paper reports findings from a telephone survey focused on second generation South Asians residing in the City of Brampton's ethnic enclaves, a suburban municipality in Toronto's Census Metropolitan Area (CMA). The primary question framing the research presented in this paper is to understand the housing preferences and residential location choices of South Asian second generation immigrants living in ethnic enclaves. Among immigrant groups, there is a great deal of cultural importance placed upon homeownership, and many immigrants possess a strong desire to own their home within the first generation (Kim \& Boyd, 2009, p. 12; Ozuekren \& van Kempen, 2002). It is important to begin to understand the nature of intergenerational change in ethnic enclaves, and how it might be affected by life cycle and socio-economic transitions. This paper will address the following questions: What factors determine a desirable place to live for second generation South Asians? What are the group's main priorities when deciding where to settle? Ultimately, understanding some of the dynamics that shape the residential housing preferences and future decisions of second generation South Asians will enhance our ability to assess the current status and future development of ethnic enclaves and suburban cities.

This paper proceeds in four parts. First, we examine the relevant literature on second generation settlement, educational attainment and homeownership. Second, we discuss details

\footnotetext{
${ }^{1}$ Second generations are those who are born in Canada, with at least one foreign-born parent (Statistics Canada, 2006).
} 
of the case study with regard to the ethnic group and suburb. Third, a brief overview of the methods and procedures will lead into the final section, which discusses the findings and analysis on second generation South Asian future residential preferences and housing choices.

\section{Defining Concepts \& Theoretical Framework}

It is important to make clear the terms being used in this study. Many of the concepts are understood in different ways by scholars as they are not completely objective, can be strongly influenced by the context in which they are interpreted in, and are continually changing given their dynamic nature. However, a problem with the taxonomy of terms is that they can be exhausted to a point where they become perplexing and possibly controversial. The intention of this study is not to argue the meaning of these terms but simply make clear their use and definition for a clearer understanding.

\section{Settlement Theories}

There is a sizeable body of research concerned with immigrant residential settlement patterns. Most of the early theories on ethnic residential patterns hypothesize that immigrants are underprivileged and thus settle close together in ethnic enclaves until their socioeconomic status improves, allowing them to settle in the higher status suburbs (Burgess, 1925; Duncan \& Duncan, 1957; Gans, 1992; Massey \& Denton, 1987; Peck, 2005). These theories were developed on the experiences of earlier European settlement groups, and may not explain the experiences of recent visible minority groups who have distinctive cultural backgrounds and economic structural labour market experiences (Fong \& Wilkes, 2003). These theories are also limiting in that they assume immigrants are socioeconomically disadvantaged and that socioeconomic mobility can be used as a measure of their integration into society (Balakrishnan \& Hou, 1999, p. 201; Boyd, 2002; Hiebert, 2000). Balakrishnan (1990) also criticised traditional theories that assume involuntary segregation and the formation of ghettos, where in Canada this may not be the case (Balakrishnan, Maxim, \& Jurdi, 2005; Bauder \& Sharpe, 2002; Fong, 1996; Logan, Alba, \& Zhang, 2002).

More recently, there have been theories suggesting that settlement in city centres is also a sign of success and integration. Traditionally, settlement to the 'poor' inner city by immigrants was considered an initial step until they were able enough to settle in the suburbs (Burgess, 1925; Massey \& Denton, 1987). However, some of these longstanding inner city immigrant communities, as the case of Cabbagetown in Toronto, are sites for gentrification where the neighbourhoods undergo increased socioeconomic achievement of residents, renovations and rising prices (Bauder \& Sharpe, 2002; Hiebert, 2000). The presence of a highly sought-after neighbourhood and its unique culture may become attractive in the housing market and existing residents could become displaced (Lewis \& Donald, 2009; Thomas \& Darnton, 2006). 
For newcomers, these neighbourhoods may be too expensive, but they do provide an example of how the views of urban living have shifted. The arrival of more highly skilled immigrants may also lead to settlement in major urban centres according to Florida (2001). This theory argues that highly skilled and 'creative professionals' are attracted to these chic urban places (not traditional communities such as the suburbs) that offer certain activities, various amenities, quality of life factors, vibrant public spaces, diverse communities, and job opportunities (Delisle \& Shearmur, 2010, p. 308; Florida, 2002; Florida, 2004; Thomas \& Darnton, 2006, p. 155).

\section{Ethnic Enclaves}

Before beginning to analyse suburban ethnic enclaves, it is important to understand the meaning and history behind this unique form of urban settlement. However, the definition of the ethnic enclave is continually changing. Ethnic enclaves are said to have progressed from areas of involuntary segregation and discrimination to being starting points for immigrants and a desirable destination for others who have diverse socioeconomic backgrounds (Logan, Alba, \& Zhang, 2002, p. 302; Qadeer \& Agrawal, 2010, p. 318; Peach, 2005; Marcuse, 2005). Qadeer and Agrawal (2010) identify ethnic enclaves as the formation of "an axis or band of high-ethnicdensity territories... surrounded by zones of lower ethnic concentrations" (p.315) (see figure 1 for Brampton as an example). Furthermore, the degree to which an ethnic enclave is prominent is defined differently by many but all ethnic enclaves in their most general sense exhibit large residential spatial concentrations where a single ethnic minority group is prominent (Bauder \& Sharpe, 2002; Walks \& Bourne, 2006). This study uses the indicator of $50 \%$ or above as being a concentrated ethnic enclave and these census tracts $(\mathrm{CT})^{2}$ were the focus in this investigation (figure 1).

Contrary to the assumptions of the human ecology model (Burgess, 1925), Doucet's (1999) 'dispersed city' hypothesis showed that the socioeconomic status of immigrants has changed, where the previously homogenous suburb areas have become reception zones for immigrants. New suburban ethnic enclaves in Canada are comprised of recent, more wealthy immigrants versus the older inner city ethnic enclaves which were mainly comprised of postwar southern European immigrants (Zucchi, 2007, p. 19). In Canada, ethnic enclaves can attract long-term immigrant residents, the second generation and other members of society (Logan, Alba, \& Zhang, 2002, pp. 300-302). In Toronto, this has allowed immigrants to settle with the population as a whole and locate directly to the periphery creating more heterogeneous communities (Balakrishnan \& Hou, 1999; Balakrishnan, Maxim, \& Jurdi, 2005; Hiebert, 2000; Kalbach, 1990; Ray, Haiseth, \& Johnson, 1997; Teixeira, 2007, p. 499). This trend toward voluntary clustering persists so that social interactions can be maximised to sustain ethnic stores, entertainment, restaurants, maintain heritage/culture, language, values, norms, familiar

\footnotetext{
${ }^{2}$ Census tracts are small geographic areas that can contain a population of 2,500 to 8,000 (Statistics Canada, 2006).
} 
surroundings, economic assistance, gain employment and access to other resources (Balakrishnan, Maxim, \& Jurdi, 2005; Borjas, 2006; Logan, Alba, \& Zhang, 2002; Peach, 2005; Zhou, 1992).

In their investigation of immigrant settlement patterns and the spatial assimilation theory, Alba, Logan, Stults, et al. (1999) raise the question: "What will be in the impact of suburban residence on contemporary immigrant groups, especially on the generations who grow up in suburbia?" (p.458). In this paper we look further ahead and ask what second generation South Asians' future residential preferences are, and which factors influence their settlement choices?

\section{South Asians}

South Asians are persons, other than Aboriginal peoples, who are non-Caucasian in race or nonwhite in colour and whose ethnic background is identified as Bangladeshi, Bengali, East Indian, Goan, Gujarati, Kashmiri, Pakistani, Punjabi, Nepali, Sinhalese, Sri Lankan, Tamil, or South Asian in the Canadian census form (Statistics Canada, 2006). This characterization is used as the standard definition in this study. It should be noted that there is tremendous intra-group diversity within immigrant populations due to differences in socioeconomic backgrounds, places of origin, and settlement patterns (Zhou \& Lin, 2005) and the terms visible minority and South Asian can be debated. Myles and Hou's (2003) caution that "skin colour alone does not produce shared identities" and that "the 'average' experience of Chinese, South Asian and Black families potentially conceals important differences among immigrant populations that are internally divided by national origin, religion, and other characteristics" (p.28). Ghosh (2007) also shows how very different sociospatial patterns and outcomes of South Asian groups can diverge significantly between subgroups such as Indian Bengalis and Bangladeshis, and Lo and Wang (1997) made similar points about subgroup variances within the broad category of 'Chinese' (Mendez, b, 2009, p. 102). But, the term is relevant as a category of assessment in so far as it represents a form of official categorization for data collection. In some ways it is also representative of broadly similar cultural experiences of immigration from the global south (Portes \& Zhou, 1993), some similar experiences of racialization and labour market deskilling (Bauder, 2003), and shared housing trajectories (Balakrishnan \& Hou, 1999; Bauder \& Sharpe, 2002) and educational attainment outcomes (Picot \& Hou, 2011). There are also other cultural traits that are relevant such as the importance placed on marriage and family ties (White, 1994; Zhou, 1997), and educational and professional development especially when invested in children (Coleman, 1990; Portes \& Zhou, 1993).

\section{Understanding Second Generations}

\section{Settlement in Ethnic Enclaves}


Further development on the ecology model is made through the 'segmented assimilation theory' proposed by Portes and Zhou (1993) on the study of second generations settlement patterns. They argue that different ethnic groups experience various types of residential patterns and not just linear assimilation. Portes and Zhou (1993), among other scholars (Boyd, 2002; Gans, 1992; Perlmann \& Waldinger, 1997; Portes \& Zhou, 1993), discuss three possible relationships: traditional upward mobility and assimilation to the host society, opposite downward mobility and ethnic segregation (also known as second generation "decline", "revolt", or "underclass"), or upward mobility while sustaining ethnically homogenous immigrant communities (most often associated with ethnic enclaves where second generations are present). Logan, Alba and Zhang (2002) called their similar model the 'new assimilation' theory where immigrant groups maintain ethnic enclaves longer than traditional theories and choose against spatial assimilation by forming more durable ethnic communities and giving rise to positive and growing enclave effects through local homeownership and improved socioeconomic achievements to some extent (Borjas, 2002; Coleman, 1990; Portes \& Schauffler, 1994; Zhou, 1997). Boyd (2002) noted that the Canadian experience does not show visible minorities contributing to the segmented or underclass assimilation theories given their higher educational attainment levels.

Recent findings also suggest that immigrants and their offspring favour living in cities surrounding major urban areas within commuting zones allowing them access to the job centres of Montreal, Toronto and Vancouver (Qadeer \& Agrawal, 2010; Reitz \& Sommerville, 2004). Many of these metropolitan centres have major ethnic enclaves in their surrounding suburban cities, as is the case with Brampton. Fong and Wilkes (2003) conducted a multivariate analysis of 17 groups in 12 Canadian cities using various factors and concluded that residential segregation among European and visible minority groups is unlikely to decrease in the future. Qadeer and Agrawal (2010) confirm this in their study of ethnic enclaves in Toronto demonstrating an increase in concentration for the Jewish, Chinese, and South Asian populations. In general, studies show a hierarchy of residential segregation among groups in Canada where whites are the least clustered and minorities the most concentrated, even when controlling for socioeconomic status (Balakrishnan T. R., 1982; Balakrishnan, Maxim, \& Jurdi, 2005; Kalbach, 1987; Richmond, 1967).

\section{Educational Attainment}

A large and growing body of literature has shown second generation immigrants to have better prospects than their parents given that their educational attainment exceeds that of their parents (Boyd \& Grieco, 1998; Farley \& Alba, 2002; Fong, 1996). More specifically, second generation visible minority immigrants have had the highest educational attainment, even when compared to their Canadian-born counterparts and the third-and-higher generations 
(Aydemir \& Sweetman, 2006; Boyd, 2002; Boyd \& Grieco, 1998; Picot \& Hou, 2011; Yan, Lauer, \& Jhangiani, 2008). Prominent among these studies is Aydemir and Sweetman's (2006) findings showing $37.8 \%$ of the second generation with a bachelor's degree or higher, compared to $31.8 \%$ of the third-and-higher-generation population that did not belong to a visible minority. Also, second generation Canadians have a university participation rate of $54.3 \%$ compared to $37.7 \%$ for the third-and-higher generations, accounting for about one year of education more than the third-and-higher generation (Picot \& Hou, 2011, p. 9).

\section{Education \& Settlement}

When studying the settlement patterns of second generation visible minorities in conjunction with their educational attainment, findings are often contradictory. Second generation residential segregation has shown to persist when social class is controlled for, and even as their education level exceeds that of their parents (Balakrishnan \& Selvanathan, 1990; Boyd, 2002; Coleman, 1990; Hiebert, 2000; Kalbach, 1990; Logan, Stults, \& Farley, 2004; Walks \& Bourne, 2006). In particular, Kalbach (1990) found the same level of segregation for many second generation groups in Toronto. There is little evidence that suggests the retention of ethnic attachment limits human capital success or impacts levels of education in any negative way (Retiz \& Sklar, 1997, p. 253), although some still argue that there may be other negative consequences from continued clustering (Balakrishnan \& Hou, 1999; Djajic, 2003; Frost, 2010). However, many studies show that second generation educational achievement may even be improved through continued settlement in ethnic enclaves since tight knit communities may encourage young immigrants to pursue higher education through the sharing of similar values and obligations, social support systems, a strong sense of family, and the monitoring of children's activities in the community (Coleman, 1990; Portes \& Schauffler, 1994; Zhou, 1997). This can also be attributed to and the promotion of values that encourage hard work (Portes \& Schauffler, 1994; Zhou, 1997). On the other hand, some scholars argue that residential segregation may decrease once education increases (Boyd \& Grieco, 1998; Farley \& Alba, 2002; Fong, 1996) but do not indicate where they choose to settle instead.

\section{Homeownership}

There is still some debate as to whether immigrants are better off than the non-visible minority population in terms of socioeconomic achievement (Hiebert, 2000; Reitz, Zhang, \& Hawkins, 2011) but many have demonstrated the ability of visible minority immigrants to attain owneroccupied housing at a faster rate than the Canadian-born population (Kim \& Boyd, 2009). Mendez (2009) reported that homeownership decreases with generational distance from immigration, although Kim and Boyd (2009) found that homeownership is consistent in Canada's three metropolitan regions where it rises after 20 years of residence in Canada for 
immigrants and stabilizes up until the third-plus generation when it begins to fall. They find "that this adaptive process occurs regardless of the local housing context. However, when we differentiate homeownership by housing type, we find that the local context is as important for understanding ownership patterns as is generational status" (Kim \& Boyd, 2009, p. 15). After examining the existing literature, it seems the higher socioeconomic status of second generation South Asians increases their homeownership prospects, freedom of choice, and ability to obtain the housing preferences they desire more so than their parents and other groups (such as the third-plus generation). Drawing from this literature, this study examines whether second generation South Asians will continue to reside in suburban ethnic enclaves or search for housing elsewhere.

\section{Life Cycle}

The heart of this paper is to understand the decisions people make when determining where to live. However, what has yet to be considered is when these individuals make these vital choices. One theory which plays a critical role in answering this question is the life cycle theory. The family life cycle perspective can be understood as "the changing demographic characteristics of a household as it progresses from initial formation to dissolution" (Clark \& Onaka, 1983, p. 47; White, 1994). Rossi's (1955) conceptualization hypothesizes that housing need or unsuitability comes from changes that occur in the household life cycle and these changes then alter the preferences and needs of the individual or family. The typical process as Lansing, Mueller, and Barth (1964) illustrate is the following: a new married couple demands a small dwelling in a high density neighbourhood close to the city core; with an increase in age and family size, an increased demand for space and suburban living arises; lastly, as family size decreases (due to departure of children), a trend back toward smaller units and higher densities in the city centre are desired. Others have borrowed from this thesis with more detailed phases such as prechild, childbearing, child-rearing and launching, post-child, and later life (Foote, Abu-Lughod, Foley, \& Winnick, 1960; Murdie, Chambon, Hulchanski, \& Teixeira, 1999). Any changes in social norms and the transition into adulthood is seen as part of the life course theory and is indicated by events in the development of one's life: ending schooling, getting married, having children, becoming a fulltime member of the labour force or establishing independent living arrangements (Dieleman, 2001; Mulder \& Hooimeijer, 1999; White, 1994). Therefore the life cycle inhibits the motivation to move during any of these stages.

This theory argues that natural housing progression would move from departing the parental home in the suburbs to residing in a smaller, denser neighbourhood in the city centre. However, some studies (as argued earlier) state that settlement in ethnic enclaves may continue into the second generation thereby contradicting one another; do second generations want to reside in suburban ethnic enclaves or depart to urban centres? This study examines 
mainly the future housing preferences with less concern for the motivations causing the group to move. It is worth noting nonetheless that the process of leaving the parental home was usually only associated with marriage but now it is increasingly motivated by the preference for independence (Buck \& Scott, 1993, p. 864). Although many have criticised the model for its failure to incorporate divorced, never married individuals and non-traditional relationships, scholars have adapted a more flexible model that focuses on transitions and not stages, a greater number of outcomes or pathways, and the possibility of countertransitions (White, 1994, p. 83). In this study, I am not scrutinizing the validity of the theory or examining how the stages of the lifecycle influence second generation South Asians. Rather, the aim is to determine whether the traditional theories of the household life cycle still have an influence on residential preference from urban to suburban settlement or vice versa and what the outcomes are for those living in suburban ethnic enclaves. I examine this group during the stages of leaving home and developing independent living arrangements.

\section{The Case Study: Brampton}

\section{South Asians in Brampton}

In 2006, 54.2\% of Canada's South Asian population lived in the Toronto CMA which includes the City of Brampton (Statistics Canada, 2006) (see following section). The City of Brampton has a substantial South Asian population, approximately $31.69 \%$ of the total population and $55.56 \%$ of the total visible minority population (Statistics Canada, 2006). Most South Asian visible minorities in Brampton self reported ancestral backgrounds from the Indian subcontinent (69.0\%), Pakistani (9.3\%), Sri Lankan (7.8\%), Punjabi (4.1\%), Tamil (2.7\%) and Bangladeshi (1.8\%) (Statistics Canada, 2006). Nationality groups will not be used since there is a limited sample size and the majority of South Asian residences in Brampton self identified as 'East Indian' in origin. However, any major concerns about the degree of intra-group diversity may be countered in Brampton by the fact that the majority of respondents self-reported East Indian origin and 64.7\% reported Punjabi as their mother tongue among the South Asian regional languages (Statistics Canada, 2006), and so the prominence of East Indians should be noted when interpreting this data. The proportion of total South Asian populations residing in enclaves has also greatly increased in the Greater Toronto Area (GTA) between 2001 and 2006 from 30\% to 49\%, although they still contain a large British population (Qadeer \& Agrawal, 2010, pp. 328329). Enclaves demonstrate an increase in ethnic population concentration as they expand spatially into newly developed suburban areas (characteristic of suburban development) (Qadeer \& Agrawal, 2010, p. 330).

Brampton: The Suburb 
Stating that Brampton is a suburban community does require some attention. Taylor and Lang (2004) examined the obscurities associated with the term "suburban" and counted 50 names given to this metropolitan form in the literature. As Charney (2005) notes, this illustrates how various terminologies and means of analyzing and conceptualizing urban growth can complicate investigations of the suburbs. For the purpose of this study, Brampton is deemed a suburban city, as development occurs in greenfield sites, it is located on periphery of the Toronto urban region, it has seen rapid development in homogenous housing styles and built form to meet the needs of the baby boom population, it has higher owner occupation rates than the region, and is largely automobile dependent (Brampton, 2011; Statistics Canada, 2006); it has all the characteristics of a suburb (Charney, 2005; Lee \& Leigh, 2007). Scholars also recognize that ethnic enclaves in the GTA are present in suburban areas with higher homeownership rates and newer, sprawl-like housing developments (Qadeer \& Agrawal, 2010). Brampton has also been classified as a suburb in other studies and specific CTs have been recognized as distinct South Asian ethnic enclaves in these studies (Agrawal, 2010; Balakrishnan, Maxim, \& Jurdi, 2005; Bauder \& Sharpe, 2002, p. 216; Qadeer M. , 2005, p. 53).

Brampton is the youngest community in the Toronto CMA with a median age of 33.7 in 2006, compared to Toronto and Ontario at 37.5 years and 39.0 years, respectively. A significant second generation population is also present, and approximately $20 \%$ of the population aged 15 or older has moved, or is moving, through secondary education (Statistics Canada, 2006). Lastly, Brampton's working-age population (20-64) has also increased by $32.28 \%$ from 2001 to 2006 and now comprises 62.24\% of the total population (Statistics Canada, 2006). These statistics suggest the region's growth is linked to Brampton being seen as a desirable area for young families or young homebuyers entering the housing market. As the second generation cohort ages, Brampton is also seen as an affordable housing choice.

Figure 1: Ethnic Concentrations by Census Tract using Percent Concentrated for the City of Brampton (*note: above $50 \%$ South Asian of the total CT population is considered concentrated) 


\section{Brampton (2006) South Asian \\ Population Concentration}

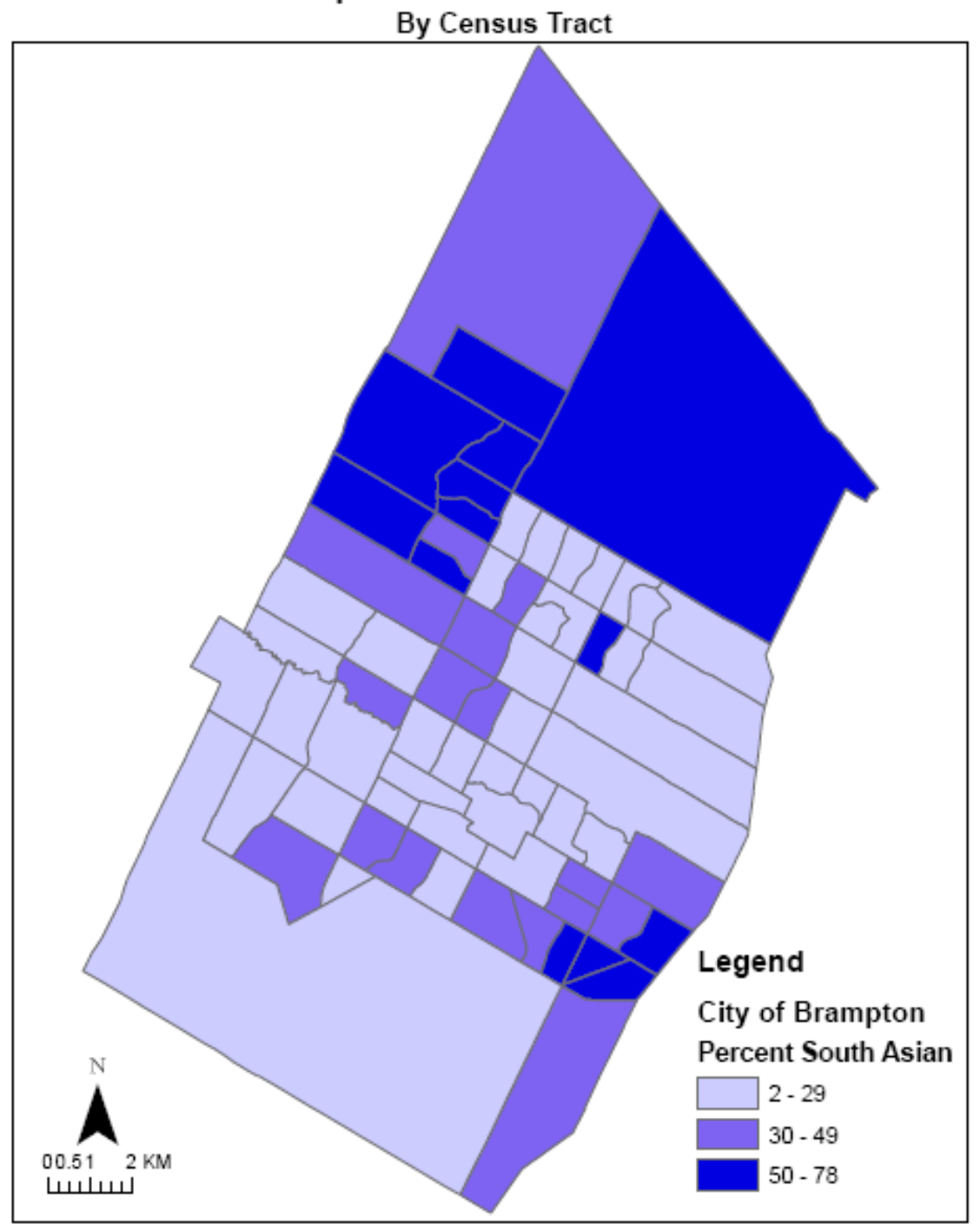

\section{Methods}

Qualitative research methods were the most appropriate for this case study given the nature of this topic which examines individual preferences based on various variables that quantitative research would be unable to accurately investigate. The qualitative methods used in this case study are telephone surveys, focus groups, and semi-structured key informant interviews. A triangulation approach aims to ensure reliability, rigour, and validity through the exploration of the question from different angles (Winston, 1997). In order to identify South Asian ethnic enclaves, analysis based on Statistics Canada 2006 data was used. The percent of South Asians residing in each $\mathrm{CT}$ (of the total population in the $\mathrm{CT}$ ) was used to determine if the $\mathrm{CT}$ was an ethnic enclave. An indicator of $50 \%$ or higher was used and fourteen CTs we idenitified with a South Asian population that represented $50 \%$ or more of the total population within the CT. 
These fourteen ethnic enclaves were located in five of the total ten wards. One ethnic enclave within each of the five wards that had the highest concentration of South Asians was selected to conduct the telephone survey in, for practicality purposes. Using the second generation South Asian values for the City of Toronto, this study approximates there to be 20,649 second generation South Asians residing in Brampton as of 2006. A telephone survey was used to examine the opinions, beliefs, characteristics, present behaviours, and trends of the broader second generation South Asian population in an ethnic enclave through nonprobability random sampling (McGuirk \& O'Neill, 2010; Neuman \& Robson, 2007). Much of the data on education level, the type of housing, average age, etc., though it is possible to access, could not be predetermined through statistical data analysis due to cost.

The telephone survey employed consisted of 14 questions in total, most of which were close-ended with a few semi-open ended questions to allow for ease of analysis and coding given time limitations of both the researcher and participants, and the costs involved in surveys. The following website allowed sample data to be collected using the reverse phone application and searching for sir names common to South Asians (Owusu, 1999); using street names and postal codes within a CT the website lists residents name and number: http://www.whitepages.ca/reverse_phone. However, this approach does present its own set of limitations (see Owusu, 1999). A participant was eligible in the survey if they were 20 years old or older, currently lived in the City of Brampton, were born in Canada and were of South Asian heritage. There were an average of 767 phone calls per CT with an average response rate of $2.3 \%$ and a total of 3930 phone calls connected. There were a total of 103 participants who completed the survey (including some surveys completed by focus group participants) Three focus groups were conducted and allowed for the gathering of detailed analysis of second generation settlement preferences, perceptions of their existing neighbourhoods, and ideas and insights about future suburban or urban neighbourhoods. The intricate socio-spatial relationship between housing, ethnic enclaves, sub/urban areas, and how the second generation experienced it were discussed. Recruitment for the focus group was sought through purposive sampling and personal networks. The results with the survey and focus group were triangulated with interviews involving housing and planning professionals as well, although these two other components will not be address in this paper.

\section{Procedure}

\section{Housing Preferences}

Studying housing choice is limited in that it only reveals partial explanations, especially when dealing with the complicated nature of immigrant offspring and their future housing preferences. Mulder (1993) defines preferences as actual transformations of overall goals during certain times in an individual's life. Preferences reveal a liking or taste in mainly ideal 
situations and have the obvious potential to change and evolve in the future (Molin, 1999). Ozuekren and van Kempen (2002) point out that work has been criticised for its emphasis on choice and lack of attention to constraints (368). Although analysing preferences is complicated, difficult, and may not reveal actual outcomes (Buck \& Scott, 1993; Dieleman, 2001), the decision to study preferences was made given the difficulty of collecting adequate and assessable data from existing sources such as Statistics Canada. In favour of this, Molin (1999) illustrates how key elements in housing preferences often remain during selection, such as the type of house, the type of neighbourhood and the location - all three elements that are examined in this study. Ozuekren and van Kempen (2002) suggest that when studying housing careers, it is most ideal to this longitudinally throughout the lives of the participants, although this approach is only feasible on a large scale in a few countries with a small number of respondents, and is often very costly. An alternative can be using cross-sectional methods (as done in this paper) and asking participants about their previous and preferred housing arrangements (Ozuekren \& van Kempen, 2002, p. 367). Given the limited time and resources available, the latter approach was taken and we asked second generations of their preferred housing type and location. To counteract many of the issues of studying preferences, using three methods of data collection aims to complement what the current trends in housing preferences are.

Similar to Buck and Scott (1993), we distinguish between participants who are "leaving home" and "living away from home". We use the more restrictive "leaving home" definition for the fact that we want to understand the housing preferences for independent residency where "living away from home" is understood as moves into institutions or other housing arrangements as a result of entry into college or work with some economic dependence on the parents. For the purpose of this study, we will view first-time home leaving as the individual's desire to move out of their parents' home into their own residence. This would most often be associated with marriage, cohabitation, or independent living, although the reasons for wanting to leave the parental home are not discussed in detail. The results of the telephone represented a demographic of young individuals mostly residing at home. The stage of the telephone participants' life cycle are mainly those prior to the stage of first-time home leaving (87 participants) and only a few who have already developed independent housing arrangements (16 participants). This also reflects the relatively young age of the population surveyed, which averaged 24.5 years old. This cohort is as close as we could get to understanding the housing desires of second generation South Asians and the future direction of suburban development. Below we identify whether they are likely to move (suburban vs. urban), the type of dwelling, in addition to the population's characteristics at a micro level since the focus is on ethnic enclaves. We also explore some reasons as to how the ethnic enclave may reinforce ideas of the life cycle given the results from the telephone survey. 


\section{Overall Findings}

\section{Characteristics of Survey Participants}

There were 55 female and 48 male participants involved in this study. Approximately $82 \%$ of those surveyed currently reside with their parents (figure 2). The last level of education completed among these participants was high school (46\%) followed by an undergrad (32\%) (figure 3). A slight majority (55\%) of participants were currently enrolled in school, with $71 \%$ attending a university to complete an undergrad (figure 4). A large portion of participants (65\%) had resided in Brampton for over 11 years (figure 5). Many of the participants had or were currently studying business or science (figure 6). Also, $74.5 \%$ of participants were employed and of that group, $60.5 \%$ of them had jobs that related to what they studied in school. Most of the cities where people worked were local. The majority $(62.3 \%)$ of participants were employed within the Region of Peel (32.5\% in Brampton and 29.9\% in Mississauga) and 15.6\% in Toronto.

Figure 2: Current Residence

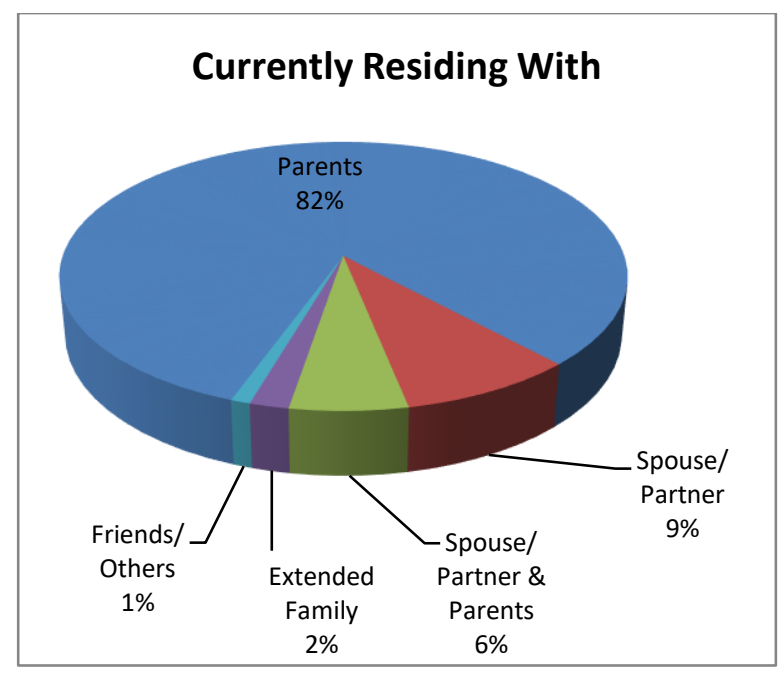

Figure 4: Currently Enrolled, Level of School
Figure 3: Last Level of Education Completed

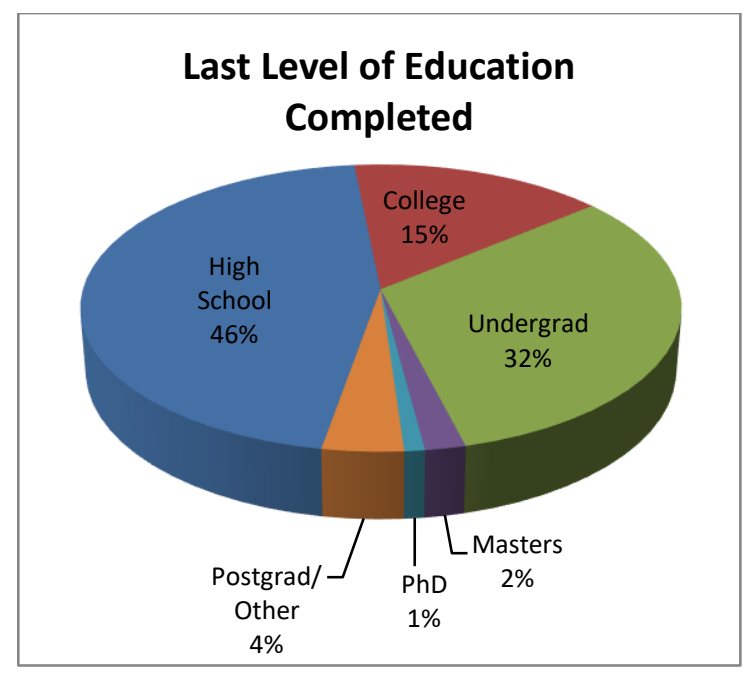

Figure 5: Years of Residence in Brampton 

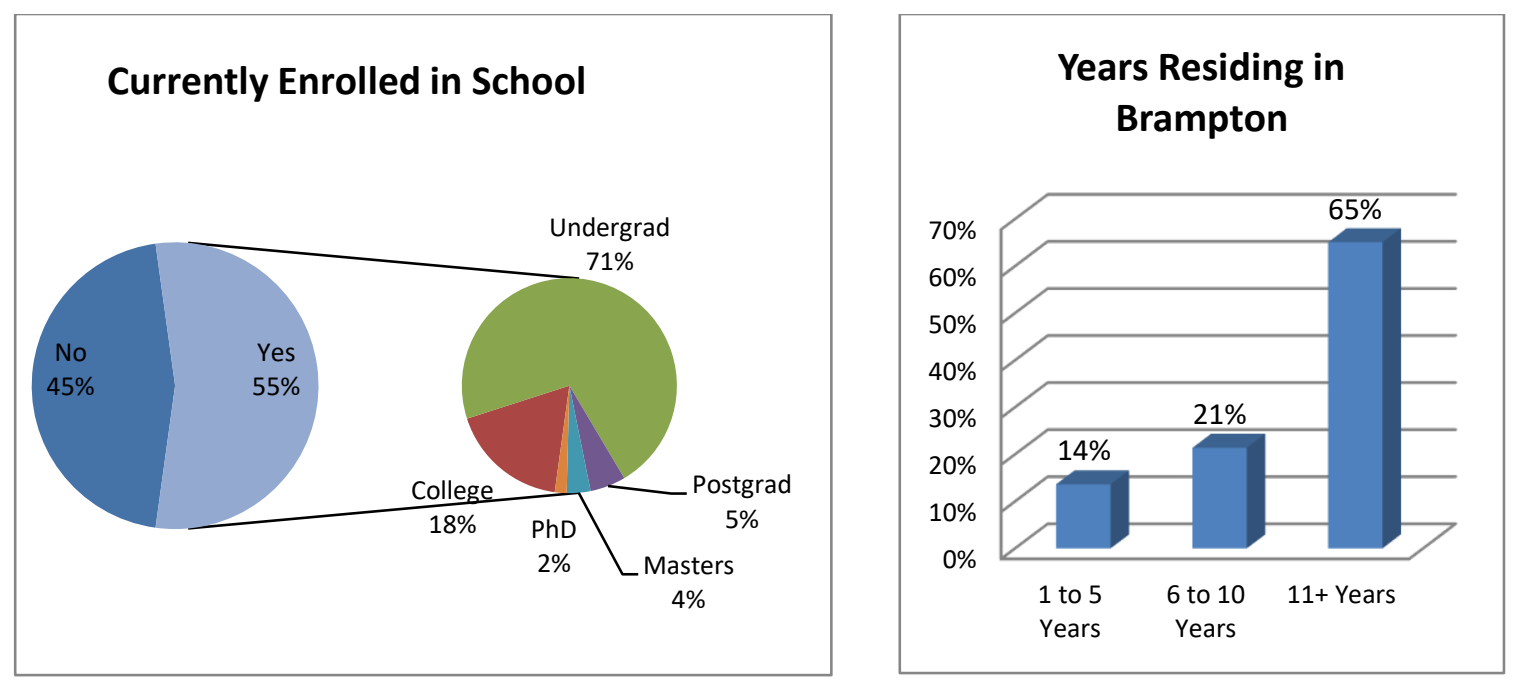

Figure 6: Area of Study in School

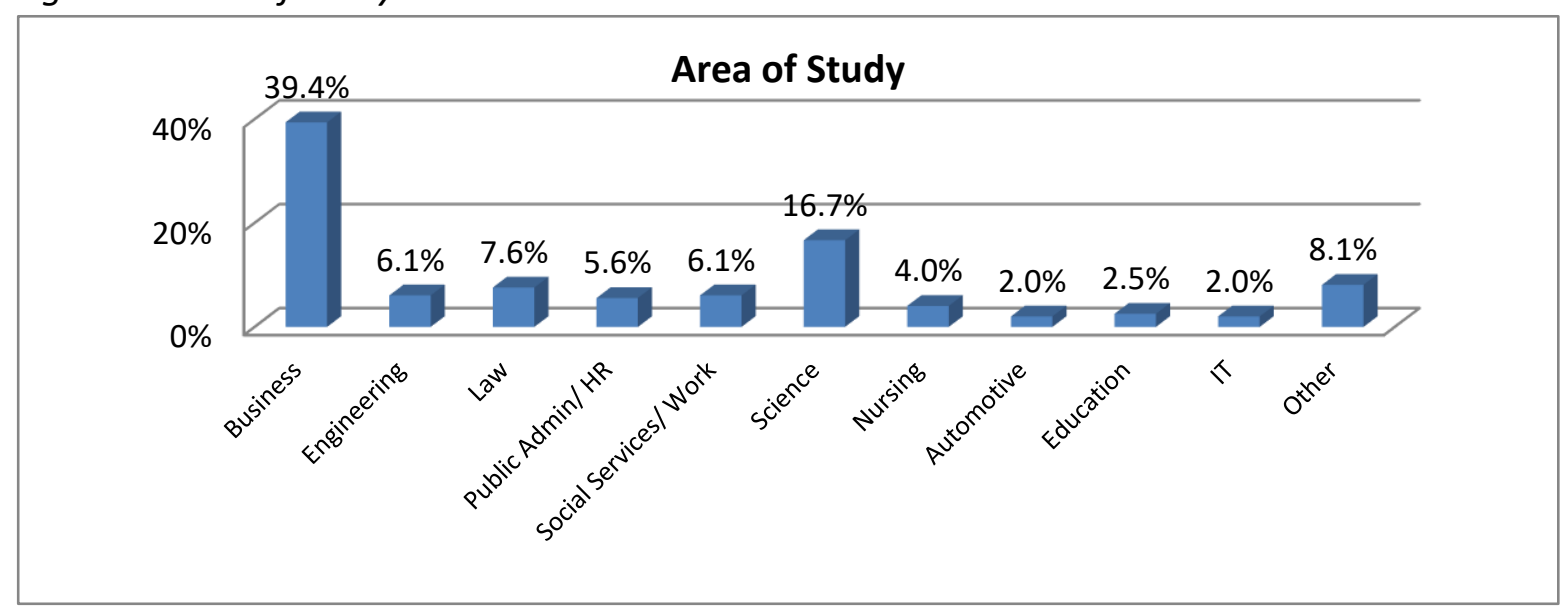

\section{Future Residence in Brampton}

Overall, second generation South Asians seem generally satisfied to very satisfied with living in the City of Brampton with a majority indicating a 3, 4, or 5 level of satisfaction on a 5 point scale (figure 7). However, when asked whether second generation South Asians would reside in the City of Brampton in the future, the response was virtually 50/50; 49.5\% responded yes and $50.5 \%$ responded no. For those who would reside in Brampton in the future, the overwhelming reason was being close to friends and family (66.0\%), while some preferred the lifestyle (14.9\%) (figure 8). Of those individuals who do not wish to reside in Brampton in the future, many said they would like a change in lifestyle (40.8\%), they disliked features of the city (18.4\%), and other undisclosed reasons (30.6\%) (figure 9).

Figure 7: Overall Satisfaction with Brampton 


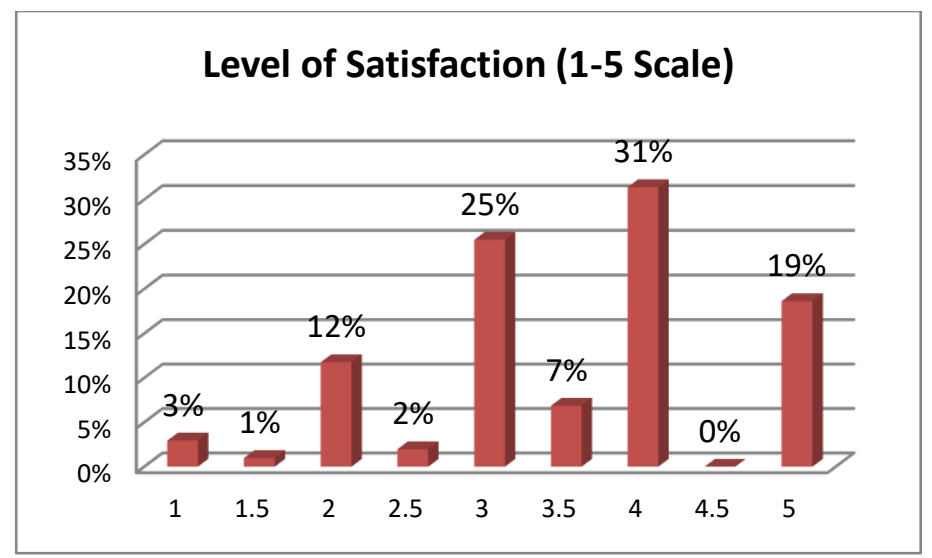

Figure 8: Reasons to Continue Residing in Brampton

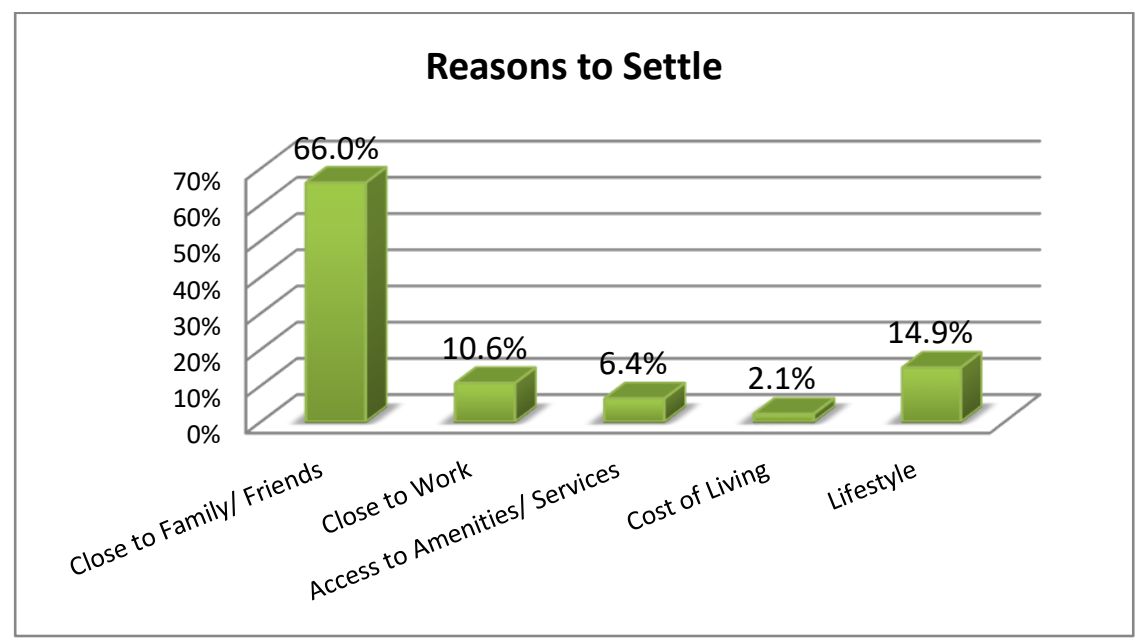

Figure 9: Reasons to Relocate out of Brampton

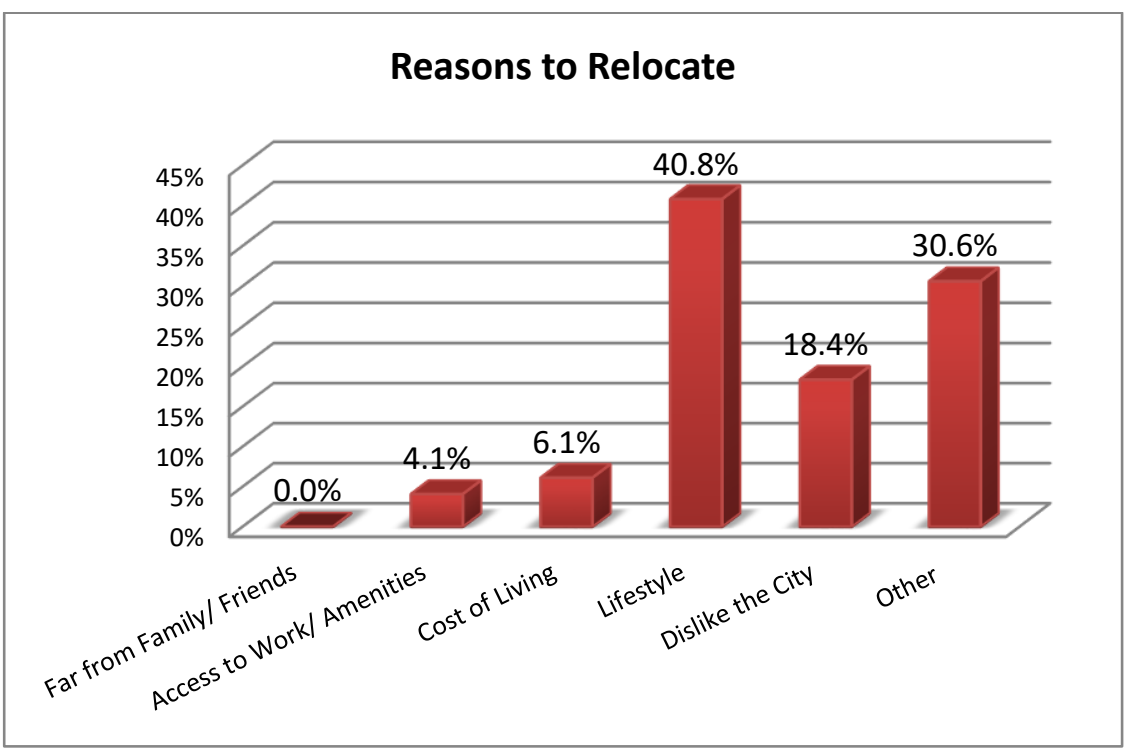




\section{Preferred Housing Characteristics}

These results show that majority of second generation South Asians prefer to live in semidetached or detached housing types (67\%) and the most important living feature is residing close to family and friends (49\%) (figure 10). Other important features when deciding where to live include living in their desired house or neighbourhood (23\%) and being close to work (19\%) (figure 11).

Figure 10: Type of House Preferred in Future

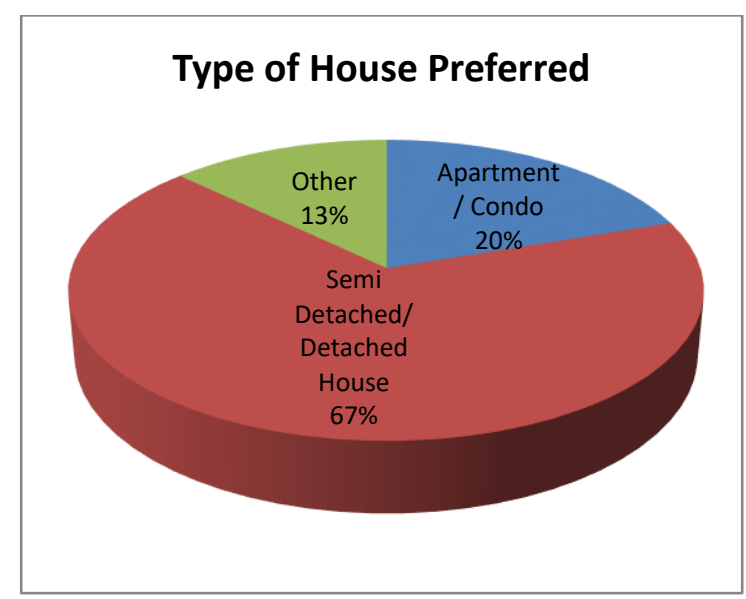

Figure 11: Most Important Living Feature

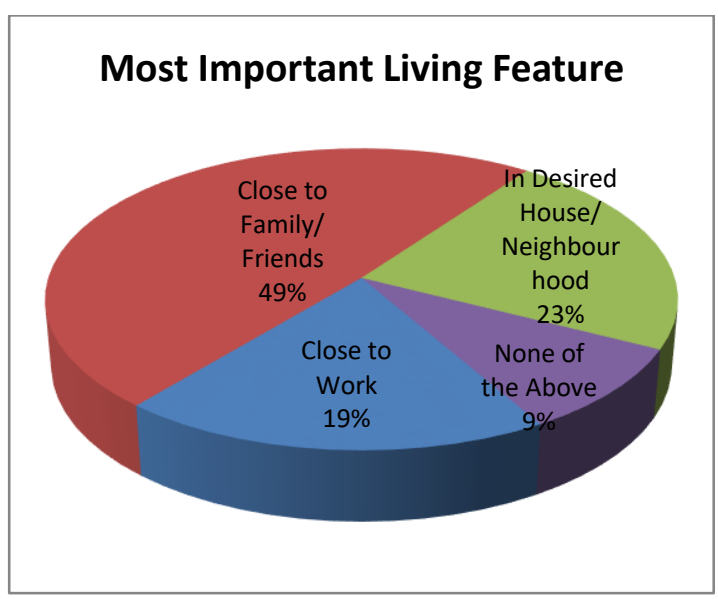

\section{Analysis \& Discussion}

\section{Age, Education \& Housing Characteristics}

The average age of survey participants, 24.5 years old, and the very large number currently living with their parents suggests that this group may be entering the leaving home stages of the life cycle in the years to come. The process of leaving the parental home was usually associated with marriage but is now increasingly motivated by the preference for independent living (Buck \& Scott, 1993, p. 864). In the South Asian culture however, there is the general belief that children and especially females are not expected to move out until they are married. One might argue that these trends could be changing, although it is not evident in our findings. Even though many individuals are currently enrolled in school (55\%) the majority are attending university (71\%) and on their way to completion. However, educational and career attainment inevitably alters housing consumption during the life cycle (Dieleman, 2001). As long as the individuals are in school they are less likely to buy homes due to mobility requirements and limited incomes (Haan, 2005, p. 10). Nonetheless, when the group does complete their schooling, as university graduates they will have higher levels of human capital that should translate into mortgage qualification, thereby increasing their likelihood of securing housing (Haan, 2005, p. 10). Also, higher educational attainment leads to increased future earnings potential, income stability and higher homeownership rates (Haan, 2005, pp. 10-11). 


\section{Future Housing Preferences: Residing in the Ethnic Enclave}

The long time residency of many participants in Brampton also makes this group of second generations ideal when understanding what the impact of living in an ethnic enclave may be on their future housing choices. For the half who said they would reside in Brampton in the future, the overwhelming reason was to be close to family and friends. Although residing in an ethnic enclave is not a necessity for second generations, this supports the notion that second generations may continue to reside in their ethnic enclave out of preference rather than constraint (Portes \& Zhou, 1993; Kalbach, 1990). The familial ties, closeness to others of the same background, and ties to their culture (Coleman, 1990; Portes \& Schauffler, 1994; Zhou, 1997) may be indicators as to why this group still wants to reside in close proximity to their family and friends. These communities exhibit a great deal of stickiness for the second generation. Being raised in an ethnic community may greatly influence the importance placed on having that sense of community even into the second generation. The tendency of second generations to continue to reside in ethnic enclaves was also evident in Kalbach's (1990) study of segregation for many second generation groups in Toronto.

The preferred type of housing is also reflective of suburban cities with $81.6 \%$ of this group wanting to reside in a semi-detached or detached type dwelling. The individuals who wish to continue to live in Brampton also have a greater number with a university degree (41.2\%) or other educational qualifications (college $13.7 \%$, masters $2.0 \%$, other $7.8 \%$, totalling $64.7 \%$ ) than among those who wish to move out of Brampton, as discussed below. This may reveal that since the education phase is mostly completed for this group, the next transition according to the life cycle theory would be to get married or find a partner and eventually enter the child bearing phase. As mentioned in the previous section, having completed school does in fact increase a person's ability to enter the housing market. According to Rossi's (1955) perspective, these young adults should want to reside in dense urban centres and then eventually move to the suburbs during the child bearing phase. However, half of the respondents said they would want to continue residing in the suburb of Brampton, not residing in an urban centre at all. The average age of this group is 25.1 and the life cycle theory would contend that during the child bearing stages, there is a common view in society that the suburbs are appropriate places for raising children in addition to being a symbol of socioeconomic achievement (Boyd, 2002; Gans, 1992; Kim \& Boyd, 2009). Also, it is common within the South Asian culture that children be raised with the support of their immediate and extended family which may also support the desire to reside in Brampton. This tentatively suggests that second generation South Asians who want to continue to reside in the suburbs may not be attracted to the experience of urban living, or rather, are planning on launching their independent family formation stage in the same area where their families reside. 


\section{Future Housing Preferences: Moving out of the Ethnic Enclave}

When examining the motives of the half who would not reside in Brampton in the future, there was a mixed response. A large portion said they would like to see their lifestyle change (40.8\%) and the remaining said that they disliked Brampton or wanted to relocate for 'other' reasons (30.6\%). There seems to be other underlying factors that have resulted in $30.6 \%$ of respondents selecting 'other' reasons. Some participants elaborated on what 'other' means. Three out of a total of fifteen participants selecting 'other' said there was a lack of diversity (too ethnocentric) and two participants said there was overcrowding or too much traffic. Other single responses included increasing property taxes, poor infrastructure and hospital, not pedestrian friendly, not an ideal place to raise children and an unsafe city (increased crime). Two people also said that the city did not meet their expectations compared to where they lived before (often Mississauga was used as a comparative).The findings from the focus group further illustrate what features this group likes and dislikes about the city and what aspects one would classify as 'other' (but are not included in this paper given space constraints). Of the participants that said no, a slight minority (46.2\%) would rather live in an urban centre or downtown area compared to $36.5 \%$ that would continue to reside in another suburban city. This falls in agreement with those respondents who said they would not reside in the City of Brampton because they would like to see a change in lifestyle. Kim and Boyd's (2008) study is particularly noteworthy because "With the exception of South Asians, all other non-White groups are more likely than Whites to own condos versus other housing in Toronto" (p.11). This may suggest that if South Asians are residing in urban centres, then they are not living in condominiums. This is supported by our findings since those who would like to live in an urban centre would still prefer to reside in a semi-detached or detached dwelling. Mulder and Hooimeijer (1999) suggest that people (commonly over the age of 30 , families with children, and long term couples) who initially prefer to reside in the city are often prepared to move to a suburb in order to obtain the dwelling or residential community of their preferred quality, size or tenure (p.174).

An interesting outcome is that, unlike the group that wishes to reside in Brampton in the future, this group has many individuals having only completed high school as the last level of education $(55.8 \%)$ with most still in post secondary institutions. This further supports the traditional life cycle theory since this group has yet to finish their education and it seems that they have not started to think about living independently or with a spouse or partner. This is a reasonable inference since this group is younger than the former with an average age of 23.9. This group, contrary to the suburban living group, does follow Rossi's (1955) theory and would settle in a dense urban centre. Their desire to reside in an urban city may also indicate a possible shift in housing preferences among younger generations. This group is also more likely to want to live in an apartment or condo $(28.8 \%)$ than the group wanting to continue residing in Brampton (10.2\%), indicating a possible shift in ideology. As Dieleman (2001, p.250) suggests, 
young adults between the ages of 20 and 25 in developed societies are the most mobile segments of the population. However, there is some possibility that the values of being raised in the suburbs could carry onto the second generation since a significant amount (36.5\%) said they would want to continue residing in another suburban city and the influence of the child bearing phase could bring these individuals back to the suburbs.

\section{Conclusion}

The findings in this study run contrary to the results of McLeod and Ellis' (1982) study that saw no significant influence of life cycle on location choice when examining housing consumption and location using house purchasers in Perth, Australia. This paper however, examines a specific ethnic group living in a unique spatial environment - the suburban voluntary ethnic enclave. What this research indicates is that the life cycle may have an influence on where individuals choose to reside prior to the independent living and household formation phases, especially when examining comparisons across urban and suburban residences. It seems that continued residency in an ethnic enclave for second generations may in fact reinforce traditional ideas of socioeconomic success and the life cycle, at least among the South Asian population in Canada thinking about getting married and starting a family. The results of this telephone survey suggest that the ideas of socioeconomic success, especially in housing attainment held by immigrant parents are then passed onto their Canadian-born children since the majority of second generations still wish to reside in semi-detached or detached dwellings perpetuating the trend toward suburban urban form. What is somewhat unclear is whether this group will continue to reside in ethnic enclaves or move elsewhere, since the results were split $50 / 50$. Of those who do wish to reside in the ethnic enclave, they prefer to be close to family and friends. Of those who do not want to live in the ethnic enclave, most prefer to reside in an urban centre or downtown area while some simply prefer another suburban city. Although the latter group follows traditional life cycle theories, this group may show a shift toward residing in the ethnic enclave or simply the suburbs as they begin to conclude their educational careers and transition into independent living and the child bearing phase. We believe that the importance of parental ties in South Asian culture, the growth in ethnic enclaves, and more traditional life cycle values play important roles in shaping preferences of the second generation.

Since this paper is largely explorative and relies heavily on a case study, it raises many issues that require further elaboration. Investigating only one ethnocultural group within a geographically specific community limits this research's applicability to other groups and cities as it may not have an adequate number of cases (Winston, 1997). Furthermore, the cross sectional quality of this research assumes that social phenomena are static over time but preferences typically change and this relationship may only be 'true' under certain conditions (Baxter, 2010). This analysis is also hampered by small sample numbers. This research 
nonetheless opens up to other avenues for investigation to disentangle housing preferences of second generations in suburban ethnic enclaves. Future studies on the actual housing outcomes would be immensely beneficial in fully understanding the housing preferences of this group. Also, understanding whether similar preferences exist for other visible minority groups within ethnic enclaves would help to explain whether this is a South Asian phenomenon or if differentiates along ethnic lines. Despite these limitations, we feel the findings of this study indicate that a number of factors support the reproduction of suburban housing choices for South Asian Canadians through the generations, and as such indicate that the planning and environmental challenges linked with suburban growth surrounding large immigrant receiving metropolitan areas will remain a policy issue for some time to come in Canada. 


\section{Bibliography}

Agrawal. (2010, February 4). The new ethnic enclaves. Retrieved March 1, 2010, from Toronto Star[Politics]: $h$ ttp://www.themarknews.com/articles/884-the-new-ethnic-enclaves

Agrawal, S. K. (2006). Housing adaptation: A study of Asian Indian immigrant homes in Toronto. Canadian Ethnic Studies, 38 (1).

Alba, R. D., Logan, J. R., Stults, B. J., Marzan, G., \& Zhang, W. (1999). Immigrant groups in the suburbs: A reexamination of suburbanization and spatial assimilation*. American Sociological Review, 1999, 64, 446460.

Aydemir, A., \& Sweetman, A. (2006). First and secone generation immigrant educational attainment and labour market outcomes: A comparison of the United States and Canada. Institute for the Study of Labor Discussion, Paper No. 2298.

Balakrishnan, T. R. (1982). Changing patterns of ethnic residential segregation in the metropolitian areas of Canada. Canadian Review of Sociology and Anthropology , 19, 92-110.

Balakrishnan, T. R., \& Hou, F. (1999). Socioeconomic integration and spatial residential patterns of immigrant groups in Canada. Population Research and Policy Review , 18, 201-217.

Balakrishnan, T. R., \& Selvanathan, K. (1990). Ethnic residential segregation in metropolitan Canada. In S. Halli, F. Travato, \& L. Dreidger, Ethnic Demography (pp. 339-413). Ottawa: Carleton University Press.

Balakrishnan, T. R., Maxim, P., \& Jurdi, R. (2005). Social class versus cultural identity as factors in the residential segregation of ethnic groups in Toronto, Montreal and Vancouver for 2001. Canadian Studies in Population, 32 (2), 203-227.

Balakrishnan, T. (2001). Residential segregation and socio-economic integration of Asians in Canadian cities. Canadian Ethnic Studies , 33 (1), 121-136.

Barnett, J. M. (2002). Focus Groups Tips for Beginners: TCALL Occassional Research Paper No.1. Texas: Texas Center for Adult Literacy \& Learning .

Bauder, H., \& Sharpe, B. (2002). Residential segregation of visible minorities in Canada's gateway cities. Canadian Geographer , 46 (3), 204-222.

Baxter, J. (2010). Case studies in qualitative research. In I. Hay, Qualitative Research Methods in Human Geography (pp. 81-97). New York: Oxford University Press.

Borjas, G. (2002). Homeownership in the immigrant population. Journal of Urban Economics , 44 (2), $448-476$.

Borjas, G. (2006). Making it in America: Social mobility in the immigrant population. Journal Issue: Opportunity in America , 16 (2).

Boyd, M. (2002). Educational attainments of immigrant offspring: Success or segmented assimilation? International Migration Review, 36 (4), 1037-1060.

Boyd, M., \& Grieco, E. M. (1998). Socioeconomic achievements of the second generation in Canada. International Migration Review , 853-876.

Boynton, P. M., \& Greenhalgh, T. (2004). Hands-on guide to questionnaire research: Selecting, designing, and developing your questionnaire. BMJ , 328, 1312-1316.

Brampton, C. o. (2011). Discover Brampton's History. Retrieved November 12, 2011, from Brampton: http://www.brampton.ca/en/Arts-Culture-Tourism/heritage/Pages/Brampton's-History.aspx

Brenton, R. (1964). Institutional completeness of ethnic communities and the personal relatiosn of immigrants. American Journal of Sociology, 70 (2), 193-205.

Buck, N., \& Scott, J. (1993). She's leaving home: But why? An analysis of young people leaving the parental home. Journal of Marriage and Family, 4, 863-874.

Burgess, E. (1925). The growth of the city: An introduction to a research project. In R. E. Park, W. Burgess, \& R. D. McKenzie (Eds.), The City (pp. 47-62). Chicago: University of Chicago Press. 
Cameron, J. (2010). Focusing on the focus group. In I. Hay, Qualitative Research Methods in Human Geography. (pp. 152-172). New York: Oxford University Press.

Charney, I. (2005). Re-examining suburban dispersal: Evidence from suburban Toronto. Journal of Urban Affairs , 27 (5), 467-484.

Clark, W. A., \& Onaka, J. L. (1983). Life cycle and housing adjustment as explanations of residential mobility. Urban Studies, 20, 47-57.

Coleman, J. (1990). Foundations of Social Theory. Cambridge, MA: Belknap Press of Harvard University Press.

Dieleman, F. M. (2001). Modelling residential mobility; A review of recent trends in research. Journal of Housing and the Built Environment, 16, 249-265.

Djajic, S. (2003). Assimilation of immigrants: Implications for human capital accumulation of the second generation. Journal of Population Economics , 16, 831-845.

Doucet, M. (1999). Toronto in transition: Demographics change in the late twentieth Century. Retrieved from Virtual Library: http://ceris.metropolis.net/vl/other/doucet2.html

Driedger, L. (2003). Ethnic/racial urban residential segregation in Eastern Canada. Prairie Centre of Excellence for Research on Immigration and Integration, Working Paper No. 03-03.

Duncan, O. D., \& Duncan, B. (1957). The Negro Population of Chicago: A Study of Residential Segregation. Chicago: University of Chicago Press.

Farley, R., \& Alba, R. (2002). The new second generation in the United States. International Migration Review , 36 (3), 669-701.

Fong, E. (1996). A comparative perspective on racial residential segregation: American and Canadian experiences. The Sociological Quarterly, 37 (2), 199-226.

Fong, E., \& Wilkes, R. (2003). Racial and ethnic residential patterns in Canada. Sociological Forum , 18 (4), $577-602$.

Foote, N. N., Abu-Lughod, J., Foley, M. M., \& Winnick, L. (1960). Housing choices and constraints. New York.: McGraw-Hill.

Frost, H. (2010). Being "brown" in a Canadian suburb. Journal of Immigrant \& Refugee Studies , 8 (2).

Gans, H. (1992). Second generation decline: Scenarios for the economic and ethnic futures of the Post-1965 American immigrants. Ethnic and Racial Studies , 15, 173-191.

Ghosh, S. (2007). Transnational ties and intra-immigrant group settlement experiences: A case study ofIndian Bengalis and Bangladeshis in Toronto. GeoJournal , 68 (2-3), 223-242.

Haan, M. (2005). The decline of the immigrant homeownership advantage: Life-cycle, declining fortunes and changing housing careers in Montreal, Toronto and Vancouver, 1981-2001. Ottawa: Minster of Industy .

Haan, M. (2007). The homeownership hierarchies of Canada and the United States: The housing patterns of white and non-white immigrants of the past thirty years. Centre for Migration Studies of New York, 41 (2), 433 465.

Hagestad, G., \& Neugarten, B. (1985). Age and the life course. In R. Binstock, \& E. Shanas, Handbook of Aging and the Social Sciences (2 ed., pp. 35-61). New York: Van Nostrand Reinhold.

Hiebert, D. (2000). Immigration and the changing Canadian city. The Canadian Geographer , 44 (1), 23-43.

Kalbach, W. E. (1990). Ethnic residential segregation and its significance for the individual in an urban setting. In Ethnic Identity and Equality (R. Breton, \& a. et., Trans., pp. 92-134). Toronto, ON: University of Toronto Press.

Kalbach, W. E. (1987). Growth and distribution of Canada's ethnic populations, 1871-1981. In L. Driedger (Ed.), Ethnic Canada: Identities and Inequalities (pp. 82-110). Toronto, ON: Copp Clark Pitman.

Kazemipur, A., \& Halli, S. (2000). The invisible barrier: Neighbourhood poverty and integration of immigrants in Canada. Journal of International Migration and Integration , 1 (1), 85-100.

Kim, A., \& Boyd, M. (2009). Housing tenure and condos: Ownership by immigrant generations and the timing of arrival. Canadian Journal of Urban Research . 
Lansing, J. B., Mueller, E., \& Barth, N. (1964). Residential Location and Urban Mobility. Institute for Social Research: The University of Michigan.

Lee, S., \& Leigh, N. G. (2007). Intrametropolitan spatial differentiation and decline of inner-ring suburbs. Journal of Planning Education and Research , 27, 146-164.

Li, W. (1998). Anatomy of a new ethnic settlement: The Chinese ethnoburb in Los Angeles. Urban Studies (35), 479.

Lo, L., \& Wang, S. (1997). Settlement patterns of Toronto's Chinese immigrants: convergence or divergence? Canadian Journal of Regional Science, 20 (1), 49-72.

Logan, J., Alba, R., \& Zhang, W. (2002). Immigrant enclaves and ethnic communities in New York and Los Angeles. American Sociological Review , 67 (2), 299-322.

Logan, Stults, \& Farley. (2004). Segregation of minorities in the Metropolis: Two decades of change. Demography, $41(1), 1-22$.

Marcuse, P. (2005). Enclave yes, ghetto no: Segregation and the state. In D. Varady, Desegregating the City. (pp. 15-30). Albany: State University of New York Press.

Massey, D. S., \& Denton, N. A. (1987). Trends in the residential segregation of Blacks, Hispanics, and Asians: 19701980. American Sociological Review, 52, 802-825.

McAuley, W. J., \& Nutty, C. L. (1982). Residential preferences and moving behaviour: A fmaily life-cycle analysis. Journal of Marriage and Family, 44 (2), 301-309.

McGuirk, P. M., \& O'Neill, P. (2010). Using questionnaires in qualitative human geography. In I. Hay, Qualitative Research Methods in Human Geography (pp. 191-216). New York: Oxford University Press.

McLeod, P. B., \& Ellis, J. R. (1982). Housing consumption over the family life cycle: An empirical analysis. Urban Studies, 19, 177-185.

Mendez, P. (2009). Age-at-arrival differences in homeownership attainment among immigrants and their foreignborn offspring in Canada. Population, Space and Place, 15, 19-36.

Mendez, P. (b, 2009). Immigrant residential geographies and the 'spatial assimilation' debate in Canada, 19972007. International Migration \& Integration , 10, 89-108.

Molin, E. (1999). Conjoint Modelling Approaches for Residential Group Preferences. Eindhoven: Faculteit Bouwkunde.

Mulder, C. H. (1993). Migration Dynamics: A Life Course Approach. Amsterdam: Thesis Publishers.

Mulder, C. H., \& Hooimeijer, P. (1999). Residential relocations in the life course. In L. J. (eds.), Population Issues (pp. 159-186). Kluwer Academic; Plenum Publishers.

Murdie, R., Chambon, A., Hulchanski, J. D., \& Teixeira, C. (1999). Differential incorporation and housing trajectories of recent immigrant households: Toward a concpetual framework. . Toronto: Housing New Canadians Working Group, University of Toronto.

Myles, J., \& Hou, F. (2003). Neighbourhood attainment and residential segregation among Toronto's visible minorities. Statistics Canada: Business and Labour Market Analysis Division , 24, 206.

Neuman, W. L., \& Robson, K. (2007). Basics of Social Research : Qualitative and Quantitative Approaches. Toronto: Pearson Education Canada.

Owusu, T. (1999). Residential patterns and housing choices of Ghanaian immigrants in Toronto, Canada. Housing Studies , 14 (1), 77-97.

Ozuekren, A. S., \& van Kempen, R. (2002). Housing careers of minority ethnic groups; Experiences, explanations and prospects. Housing Studies, 17 (3), 365-379.

Peach, C. (2005). The ghetto and the ethnic enclave. In D. Varady, Desegregating the City. (pp. 31-48). Albany: State Univeristy of New York Press.

Peck, J. (2005). Struggling with the creative class. International Journal of Urban and Regional Research, 29 (4), 740-770. 
Perlmann, J., \& Waldinger, R. (1997). Second generation decline? Children of immigrants, past and present - A reconsideration. International Migration Review, 31 (4), 893-922.

Picot, G., \& Hou, F. (2011). Preparing for success in Canada and the United States: The determinants of educational attainment among the children of immigrants. . Statistics Canada, Social Analysis Division.

Portes, A., \& Schauffler, R. (1994). and the second generation: Bilingualism yesterday and today. International Migration Review , 28 (4), 640-661.

Portes, A., \& Zhou, M. (1993). The new second generation: Segmented assimilation and its variants. The ANNALS of the American Academy of Policy and Social Science, 530, 74-96.

Qadeer, M. (2005). Ethnic segregation in a multicultural city. In D. P. Varady, Desegregating the city: Ghettos, enclaves and inequality (pp. 49-61). Albany NY: State University of New York Press.

Qadeer, M., \& Agrawal, S. K. (2010). Evolution of ethnic enclaves in the Toronto Metropolitan Area, 2001-2006. International Migration \& Integration , 11, 315-339.

Ray, B. (1999). Plural geographies in Canadian cities: Interpreting immigrant residential spaces in Toronto and Montreal. Canadian Journal of Regional Science , 65-86.

Ray, B., Haiseth, G., \& Johnson, B. (1997). The changing 'face' of the suburbs: Issues of ethnic and residential change in suburban Vancouver. International Journal of Urban and Regional Research, 21 (75), 99.

Reitz, J. G., Zhang, H., \& Hawkins, N. (2011). Comparisons of hte success of racial minority immigrant offspring in the United States, Canada and Australia. Social Science Research , 40, 1051-1066.

Reitz, J. (2002). Host societies and the reception of immigrants: Research themes, emerging theories and methodological issues. International Migration Review, 36 (4), 1005-1019.

Reitz, J., \& Sommerville, K. (2004). Institutional change and emerging cohorts of the 'new' immigrant second generation: Implications for the integration of racial minorities in Canada. Journal of Migration \& Integration , 5 (4), 385-415.

Relph, E. (1991). Canadian urban landscapes: Suburban downtowns of the Greater Toronto Area. The Canadian Geographer, 35 (4), 421-425.

Retiz, J. G., \& Sklar, S. M. (1997). Culture, race, and the economic assimilation of immigrants. Sociological Forum, $12(2), 233-277$.

Richmond, A. H. (1967). Post-War Immigrants in Canada. Toronto: University of Toronto Press.

Rossi, P. H. (1955). Why Families Move. . Glencoe: Free Press.

Statistics Canada. (2006). 2006 community profile: Brampton. Retrieved. Retrieved September 24, 2009, from S tatistics Canada: http://www12.statcan.gc.ca/census-recensement/2006/dp-pd/prof/92591/details/page.cfm?Lang=E\&Geo1=CSD\&Code1=3521010\&Geo2=PR\&Code2=35\&Data=Count\&SearchT ext=bra

Taylor, P. J., \& Lang, R. E. (2004). THe shock of the new: 100 concepts describing recent urban change. Environment and Planning , A (36), 951-958.

Teixeira, C. (2007). Residential experiences and the culture of suburbanization: A case study of Portuguese homebuyers in Mississauga. Housing Studies, 22 (4), 495-521.

Walks, A., \& Bourne, L. (2006). Ghettos in Canada's cities? Racial segregation, ethnic enclaves and poverty concentration in Canadian urban areas. The Canadian Geographer, 50 (3), 273-297.

White, L. (1994). Coresidence and leaving home: Young adults and their parents. Annual Review of Sociology, 20, 81-102.

Winston, T. (1997). Introduction to case study. The Qualitative Report, 3 (2), 1-16.

Yan, M. C., Lauer, S., \& Jhangiani, S. (2008). Riding the boom: Labour market experiences of new generation youth from visible minority immigrant families. Canadian Ethnic Studies , 40 (2), 129-148.

Zhou, M. (1997). Segmented assimilation: Issues, controversies, and recent research on the new second generation. International Migration Review , 31 (4), 975-1008. 
Zhou, M. (1992). The Socioeconomic Potential of an Urban Enclave. Philadelphia: Temple University Press.

Zhou, M., \& Lin, M. (2005). Community transformation and the formation of ethnic capital: Immigrant Chinese communities and the United States. Journal of Chinese Overseas , 1 (2), 260-284.

Zucchi, J. (2007). A history of ethnic enclaves. Ottawa: Canadian Historical Association . 